Jessica Diebowski

Gender Acquisition in Spanish 


\section{Studies on Language Acquisition}

Series Editors

Luke Plonsky

Martha Scholten

Volume 61 


\section{Jessica Diebowski}

Gender

Acquisition

in Spanish

Effects of Language and Age

DE GRUYTER

MOUTON 
ISBN 978-3-11-070297-2

e-ISBN (PDF) 978-3-11-070304-7

e-ISBN (EPUB) 978-3-11-070312-2

ISSN 1861-4248

\section{Library of Congress Control Number: 2020952343}

\section{Bibliographic information published by the Deutsche Nationalbibliothek}

The Deutsche Nationalbibliothek lists this publication in the Deutsche Nationalbibliografie; detailed bibliographic data are available on the Internet at http://dnb.dnb.de.

(c) 2021 Walter de Gruyter GmbH, Berlin/Boston Typesetting: Integra Software Services Pvt. Ltd. Printing and binding: $\mathrm{CPI}$ books $\mathrm{GmbH}$, Leck

www.degruyter.com 
«Mi nono no había dejado otra herencia sino cartas en malicioso, fotos desteñidas [...]. Salvo la moto Indian. Dudé que hubiera sido tan perezoso como para poner un anuncio económico del domino El Mercurio con el popular «Moto vendo». Es decir, el moto - como acotó hasta que dejó de hablar de ella incapaz de entender la lógica del español que permitía que un sustantivo que terminara en «o» tuviera artículo femenino - era parte de una herencia que yo no sólo debía administrar sino también descifrar.»

- Antonio Skármeta (2001: 111): «La chica del trombón» 

To my beloved grandfathers and parents who have always believed in me and given so much of themselves. 
